\title{
Co-immobilized Alcohol Dehydrogenase and Glucose Dehydrogenase with Resin Extraction for Continuous Production of Chiral Diaryl Alcohol
}

Jieyu Zhou

Jiangnan University

Yanfei Wu

Jiangnan University

Qingye Zhang

Jiangnan University

Guochao Xu

Jiangnan University

YE NI ( $\nabla$ yni@jiangnan.edu.cn )

Jiangnan University https://orcid.org/0000-0003-4887-7517

\section{Research Article}

Keywords: flow reaction, alcohol dehydrogenase, co-immobilization, diaryl ketone, in situ recovery

Posted Date: February 17th, 2021

DOI: https://doi.org/10.21203/rs.3.rs-238951/v1

License: (9) This work is licensed under a Creative Commons Attribution 4.0 International License.

Read Full License

Version of Record: A version of this preprint was published at Applied Biochemistry and Biotechnology on April 7th, 2021. See the published version at https://doi.org/10.1007/s12010-021-03561-5. 
1 Co-immobilized Alcohol Dehydrogenase and Glucose Dehydrogenase with Resin

2 Extraction for Continuous Production of Chiral Diaryl Alcohol

3

4 Jieyu Zhou, Yanfei Wu, Qingye Zhang, Guochao Xu, Ye Ni*

5

6 Key laboratory of industrial Biotechnology, Ministry of Education, School of

7 Biotechnology, Jiangnan University, Wuxi 214122, Jiangsu, China.

8

9

$10 \quad$ Corresponding author

11 Tel/Fax: +86-510-85329265

12 Email: yni@jiangnan.edu.cn

13 


\section{Abstract}

$\mathrm{Ni}^{2+}$-functionalized porous ceramic/agarose composite beads (Ni-NTA Cerose) can be used as carrier materials to immobilize enzymes harboring a metal affinity tag. Here, a $6 \times$ His-tag fusion alcohol dehydrogenase Mu-S5 and glucose dehydrogenase from Bacillus megaterium (BmGDH) were co-immobilized on Ni-NTA Cerose to construct a packed bed reactor (PBR) for the continuous synthesis of the chiral intermediate $(S)$ (4-chlorophenyl)-(pyridin-2-yl) methanol [(S)-CPMA]. NADPH recycling and in situ product adsorption was achieved simultaneously by assembling a D101 macroporous resin column after the PBR. Using an optimum enzyme activity ration of 2:1 (Mu-S5: $B m \mathrm{GDH})$ and hydroxypropyl- $\beta$-cyclodextrin as co-solvent, a space-time yield of 1,560 $\mathrm{g} /(\mathrm{L} \cdot \mathrm{d})$ could be achieved in the first three days at a flow rate of $5 \mathrm{~mL} / \mathrm{min}$ and substrate concentration of $10 \mathrm{mM}$. With simplified selective adsorption and extraction procedures, $(S)$-CPMA was obtained in $84 \%$ isolated yield.

\section{Keywords:}

flow reaction; alcohol dehydrogenase; co-immobilization; diaryl ketone; in situ recovery

\section{Abbreviations:}

$\mathrm{ADH}$, alcohol dehydrogenase; GDH, glucose dehydrogenase; FDH, formate dehydrogenase; CPMK, (4-chlorophenyl)(pyridine-2-yl)ketone; (S)-CPMA, $(S)$-(4Chlorophenyl)-(pyridin-2-yl) methanol; DNPH, 2,4-dinitrophenylhydrazine; PBR, packed bed reactor; Cerose, ceramic/agarose composite beads 


\section{Introduction}

In comparison to batch reactions, flow reactions are relatively new for biocatalytic preparation of value-added chemicals and active pharmaceutical ingredients, such as $(S)$-1-phenylethanol, $(R)$-flurbiprofen, fatty acid methyl esters etc. $[1,2]$. In a flow reaction, fluid containing substrates is pumped to the reactor to produce a product stream [3-6]. When a flow process is applied to biocatalysis, it can be performed by using immobilized cells or enzymes [7-11]. As a continuous process, flow reactions have advantages of improved productivity, safety, ease of modifying scale, and are especially useful for reactions with substrate/product inhibitory issues [12]. Additionally, downstream processing can become facile when using immobilized biocatalysts [13].

For coupling or multienzymatic reaction systems, co-immobilization is an ideal strategy. Co-immobilization could facilitate in situ removal of by-products, and is essential for reactions that require cofactor regeneration $[14,15]$. Co-immobilization of the main and regeneration enzymes can also facilitate the mobility of the co-factor between two enzymes. Therefore, it is critical to develop immobilization strategies favorable for preserving the activity of all involved enzymes. Additionally, the distribution of the enzyme on the support surface has a profound impact on the enzyme's overall biocatalytic activity [16]. Guián's group has developed an elegant approach in which they co-immobilize the main and recycling dehydrogenases on the same agarose-type support (activated with glyoxyl groups and metal chelates) [17]. Recently, this approach was adopted in a co-immobilized glycosyltransferase/sucrose synthase catalyzed 
system for NDP-glucose recycling [18].

Immobilized metal affinity chromatography (IMAC) has also been regarded as a potential strategy for enzyme co-immobilization. The IMAC strategy relies on coordination bonds between transition metal ions ( and certain amino acids (such as His, Cys, and Trp) [19]. Co-expression of special fusion peptides results in specific coordinations between metal ions and proteins, giving advantages such as easy operation, target-specific purification, low activity loss, and recyclable carrier materials [20-24]. His-tag is one of the most popular fusion peptide for IMAC $[25,26]$. In Böhmer and coworkers' study, a 6xHis-tag fusion alcohol dehydrogenase $(\mathrm{ADH})$ and amine dehydrogenase $(\mathrm{AmDH})$ were co-immobilized on commercial metal-ion affinity glass beads EziG to produce chiral amine in batch reactions [27]. Additionally, Heli-tag, a metal-binding site (His-Ile-His-Asn-Leu-AspCys-Pro-Asp-Cys) found in ATPase 439 from Helicobacter pylori, was identified to have strong metal affinity $[28,29]$. The Heli-tag was reported to exhibit higher affinity than the 6xHis-tag and has been successfully used for D-amino acid oxidase immobilization to obtain improved operational stability [30].

Notably, the co-immobilization strategies discussed above have mainly been applied in batch reactions. Additional aspects need to be considered when adopting coimmobilized enzymes in continuous reactions, such as operational stability and cofactor-recycling under flow mode. In a study by Dall'Oglio et al., chemical anchoring was adopted for co-immobilization of $\mathrm{ADH}$ and GDH to construct a continuous flow reactor. The stability of this system proved to be excellent during a 15-day operation 
run at a flow rate of $50 \mu \mathrm{L} / \mathrm{min}$ [31]. Peschke et al. constructed an all-enzyme hydrogel consisting of $\mathrm{ADH}$ and GDH using a self-assembling strategy, in which a stable bioconversion was operated for over 6 days at a flow rate of $10 \mu \mathrm{L} / \mathrm{min}$ [32]. However, activity loss caused by covalent anchors and insufficient structural rigidity of the allenzyme hydrogel restricted the flow rate of the continuous reaction. Moreover, a continuous flow of cofactor was required in both studies. A regenerative electrochemical method [33, 34] and cofactor immobilization [35] have been reported for cofactor recycling in continuous flow biocatalysis; however, these studies were limited by complex immobilization procedures or reusability of immobilized carriers [36]. Given these limitations, we proposed a co-immobilization strategy for $\mathrm{NADP}^{+} / \mathrm{NADPH}$ reutilization and regeneration with in situ product extraction in a continuous reaction.

In this study, a non-ionic adsorptive resin was used for $\mathrm{NADP}^{+}$recycling due to its specific adsorption of non-polar or low-polar organic compounds from aqueous solutions. Herein, we designed an $\mathrm{NADP}^{+} / \mathrm{NADPH}$ regeneration strategy for a continuous flow reaction catalyzed by co-immobilized ADH/GDH. The asymmetric reduction of (4-chlorophenyl)(pyridine-2-yl)ketone (CPMK) catalyzed by Mu-S5 (a mutant of $K p \mathrm{ADH}$ from Kluyveromyces polyspora) [37, 38] was investigated as the model reaction. The chiral product $(S)$-(4-Chlorophenyl)-(pyridin-2-yl) methanol $[(S)$ CPMA] is an important intermediate for synthesizing the antiallergy drug bepotastine [38, 39]. BmGDH from Bacillus megaterium was used for NADPH regeneration. The 6×His-tagged Mu-S5 and BmGDH were co-immobilized on nickel-nitrilotriacetic acid- 
functionalized porous ceramic/agarose composite beads (Ni-NTA Cerose) to construct a packed bed reactor (PBR), which was followed by a D101 macroporous resin column. The feasibility of the proposed flow reaction process was validated by continuous synthesis and in situ recovery of (S)-CPMA.

\section{Materials and Methods}

\section{Microorganisms and chemicals}

Recombinant $E$. coli BL21 (DE3) strains harboring pET28-Mu-S5 and pET28-BmGDH with $N$-terminal $6 \times$ His-tag were constructed in a previous study [38]. Ni-NTA Cerose was purchased from Qianchun Bio (Yancheng, China). Macroporous resins of D101 and XDA-1 and chelating rein IRC-748 were purchased from Lebiochem, Co. Ltd. (Xian, China). (4-Chlorophenyl)(pyridin-2-yl)methanone (CPMK) and all other reagents and solvents of analytical grade and biochemical reagents were obtained from Sinopharm Chemical Reagent Co. Ltd. (Shanghai, China).

\section{Construction of N-terminal Heli-tagged Mu-S5}

Plasmid pET28-Helitag-Mu-S5 was constructed by replacing the N-terminal $6 \times$ His-tag sequence in pET28-Mu-S5. Plasmid pET28-Mu-S5 was used as the template, $6 \times$ Histag at N-terminal was replaced with Heli-tag by whole-plasmid PCR using KOD-PlusNeo DNA polymerase purchased from Toyobo (Osaka, Japan). The following upstream and downstream primers were used:

Heli-tag-F: 


\section{CATATTCATAATCTTGATTGTCCTGATTGTAGCAGCGGCCTGGTG}

Heli-tag-R:

\section{ACAATCAGGACAATCAAGATTATGAATATGGCTGCTGCCCATGGT}

The PCR protocol was as follows: $95^{\circ} \mathrm{C}$ for 2 min, followed by 15 cycles of $94^{\circ} \mathrm{C}$ for $30 \mathrm{~s}, 55^{\circ} \mathrm{C}$ for $30 \mathrm{~s}$, and $68^{\circ} \mathrm{C}$ for $2.5 \mathrm{~min}$. After $\mathrm{Dpn} \mathrm{I}$ digestion at $37^{\circ} \mathrm{C}$ for $30 \mathrm{~min}$, the PCR products were transformed into competent $E$. coli BL21 (DE3) cells and plated onto Luria-Bertani agar plates supplemented with $50 \mu \mathrm{g} / \mathrm{mL}$ kanamycin.

\section{Screening of supporting materials for enzyme immobilization}

\section{Preparation of the NTA Cerose column}

Each column ( $\Phi=72 \mathrm{~mm}, h=24 \mathrm{~mm}$ ) was packed with $1 \mathrm{~mL}$ of NTA Cerose and washed with $10 \mathrm{~mL}$ of deionized water followed by a solution of $\mathrm{NiSO}_{4}$ or $\mathrm{MnCl}_{2}(10 \mathrm{~mL}, 100$ $\mathrm{mM}$ ). The columns were then washed with $10 \mathrm{~mL}$ of deionized water to remove the unbound metal ions, and equilibrated with $100 \mathrm{mM}$ potassium phosphate buffer $(\mathrm{pH}$ 7.5). A ten-fold scale-up was used for the $10 \mathrm{~mL} \mathrm{Ni-NTA}$ column.

\section{Preparation of reaction solution}

Solution A: For $1 \mathrm{~mL}$ PBR, a mixture solution containing 20\% ethanol (v: v), $2 \mathrm{mM}$ CPMK, $2 \mathrm{mM}$ glucose and $2 \mathrm{mM} \mathrm{NADP}{ }^{+}$was prepared with $100 \mathrm{mM}$ sodium phosphate buffer at $\mathrm{pH}$ 7.0. The mixture was warmed to $30^{\circ} \mathrm{C}$ before use.

Solution B: For $10 \mathrm{~mL}$ PBR (after optimization); a mixture solution containing $20 \mathrm{mM}$ hydroxypropyl-beta-cyclodextrin (HP- $\beta$-CD), $10 \mathrm{mM}$ glucose and $10 \mathrm{mM} \mathrm{NADP}^{+}$was prepared with $100 \mathrm{mM}$ Tris- $\mathrm{HCl}$ buffer at $\mathrm{pH}$ 7.5. The mixture was incubated at $30^{\circ} \mathrm{C}$ 
for $1 \mathrm{~h}$, and then CPMK (1M in ethanol) was added to a final concentration of $10 \mathrm{mM}$.

\section{Determination of the amount of immobilized enzyme and dilution rate}

Mn-NTA and Ni-NTA Creose columns (1-mL) were prepared as described above. First, Mu-S5 was purified by Ni affinity chromatography and desalinated by ultrafiltration centrifugation. The resultant purified Mu-S5 was obtained with specific activity of 6.64 $\mathrm{U} / \mathrm{mg}$ (Table S1), and then diluted to around $10 \mathrm{U} / \mathrm{mL}$ (the actual value was determined to be $11.7 \mathrm{U} / \mathrm{mL})$.

The amount of immobilized enzyme was measured by calculating the difference in enzyme activity between inflows and outflows. It is presumed that saturation adsorption was reached when total activity in outflows was $10 \%$ of the initial activity. The enzyme activities of inflows and outflows were measured following assay method described in analysis methods. The total activity of the immobilized enzyme was equal to the difference in total activity between inflows and outflows, and the amount of immobilized enzyme could be calculated by dividing by the specific activity of Mu-S5 (6.64 U/mg). The detailed data can be found in supplemental data (Table S2).

Dilution rate: According to the optimized results, the enzyme loading was $20 \mathrm{mg}$ protein per mL of Ni-NTA Cerose (eg. $16.7 \mathrm{mg}$ protein/g Ni-NTA Cerose). Thus, 14.11 mg of purified Mu-S5 (94 U) and $5.89 \mathrm{mg}$ of purified $\mathrm{BmGDH}(47 \mathrm{U})$ were needed to construct a 1-mL PBR based on Ni-NTA/Mn-NTA Cerose. For operational convenience, $10 \mathrm{mg} / \mathrm{mL}$ solutions of both $\mathrm{Mu}-\mathrm{S} 5$ and $\mathrm{Bm} \mathrm{GDH}$ were prepared, corresponding to $1.41 \mathrm{~mL}$ and $0.596 \mathrm{~mL}$ loading volume, respectively. Then, a peristaltic pump was used to pump the reaction solution through the reactor at flow 
rates of $0.2,0.4,0.6,0.8$, and $1.0 \mathrm{~mL} / \mathrm{min}$. For a 10-mL Ni-NTA PBR, $141.1 \mathrm{mg}$ (940 $\mathrm{U})$ of Mu-S5 and $58.9 \mathrm{mg}$ (470 U) of $\mathrm{BmGDH}$ were mixed and loaded, and the flow rates were set at 2.0, 4.0,6.0, 8.0, and $10 \mathrm{~mL} / \mathrm{min}$. All of the post-column effluents were collected separately and detected by HPLC.

Dilution rate $=\frac{\text { Volumetric flow rate }(\mathrm{mL} / \mathrm{min})}{\text { Reactor volume }(\mathrm{mL})}$

\section{Analysis methods}

\section{Enzymatic activity assay}

The activity of Mu-S5 and BmGDH was spectrophotometrically determined according to the changes in absorption of NADPH or $\mathrm{NADP}^{+}$at $340 \mathrm{~nm}$ and $30^{\circ} \mathrm{C}$ with a $\mathrm{UV}-\mathrm{Vis}$ spectrophotometer using a molar extinction coefficient of $6,220 \mathrm{M}^{-1} \mathrm{~cm}^{-1}$. For Mu-S5, the assay mixture contained 1.0 mM CPMK, $1.0 \mathrm{mM} \mathrm{NADPH}$, and a proper amount enzyme in PBS buffer (100 mM, pH 7.0). For $B m \mathrm{GDH}$, the assay mixture contained 1 mM D-glucose, $1 \mathrm{mM} \mathrm{NADP}{ }^{+}$, and $10 \mu \mathrm{L}$ enzyme in PBS buffer (100 mM, pH 7.0). One unit of activity was defined as the amount of enzyme required for the depletion or production of $1.0 \mu \mathrm{mol}$ of NADPH under the aforementioned conditions.

\section{HPLC analysis}

The substrate conversion and ee value was determined using an Agilent 1100 HPLC system (USA) equipped with a Chiralcel OB-H column $(0.46 \mathrm{~mm} \times 250 \mathrm{~mm}, 5 \mu \mathrm{m}$, Diacel, Japan). The HPLC was performed at $254 \mathrm{~nm}$ using hexane:ethanol (95:5, v/v) as eluent at a flow rate of $0.8 \mathrm{~mL} / \mathrm{min}$.

\section{Activity recovery of immobilized $\mathrm{Mu}-\mathrm{S} 5$}


190

191

192

193

194

195

196

197

198

199

200

201

202

203

204

205

206

207

208

209

210

211

Since spectrophotometric determination was not applicable for immobilized $\mathrm{Mu}-\mathrm{S} 5$, the initial velocities of all entries were calculated using the substrate conversion from the first 10 min (substrate conversion $<20 \%$ ) using an HPLC assay.

A purified Mu-S5 solution of $10 \mathrm{U} / \mathrm{mL}$ was prepared as described above. The Mu-S5 solutions (40 mL) were loaded on $1 \mathrm{~mL}$ Ni-NTA and Mn-NTA PBR columns, respectively. Enzymatic activity of inflows was performed in a $2 \mathrm{~mL}$ reaction mixture consisting of $10 \mathrm{mM}$ CPMK, $10 \mathrm{mM}$ NADPH, and $250 \mu \mathrm{L}$ inflows in $100 \mathrm{mM}$ PBS (pH 7.0) at $30^{\circ} \mathrm{C}$ and $200 \mathrm{rpm}$ for $10 \mathrm{~min}$ (Fig. S1 \& Table S3).

The outflows were collected and the enzymatic activity was determined in a $2 \mathrm{~mL}$ reaction mixture consisting of $10 \mathrm{mM} \mathrm{CPMK}, 10 \mathrm{mM} \mathrm{NADPH}$, and $1 \mathrm{~mL}$ outflows in $100 \mathrm{mM}$ PBS (pH 7.0) at $30^{\circ} \mathrm{C}$ and $200 \mathrm{rpm}$ for $10 \mathrm{~min}$ (Fig. S2 \& Table S4).

The activity of immobilized Mu-S5 was determined as follows. Weight (in gram) rather than volume (in $\mathrm{mL}$ ) was used to quantify immobilized Mu-S5. The total weights of 1 $\mathrm{mL}$ of immobilized enzymes (Mn-NTA and Ni-NTA Creose) were measured to be 1.23 and $1.20 \mathrm{~g}$, respectively. Immobilized Mu-S5 was placed in a beaker containing $9 \mathrm{~mL}$ $100 \mathrm{mM}$ PBS (pH 7.0) buffer. After mixing, $100 \mu \mathrm{L}$ homogenized solution was transferred into $2.0 \mathrm{~mL}$ tubes followed by centrifugation. The liquid was then carefully removed, and the immobilized Mu-S5 were weighed. The activity of immobilized Mu$\mathrm{S} 5$ was determined in a $2 \mathrm{~mL}$ reaction mixture consisting of $10 \mathrm{mM} \mathrm{CPMK,} 10 \mathrm{mM}$ $\mathrm{NADPH}$, and about $0.01 \mathrm{~g}$ of immobilized Mu-S5 in $100 \mathrm{mM}$ PBS (pH 7.0) at $30^{\circ} \mathrm{C}$ and 200 rpm for 10 min (Fig. S3 \& Table S5). The data are summarized in Table S6.

Activity recovery $=\frac{\text { Activity of immobilized enzyme }}{\text { Inflows activity-Outflows activity }} \times 100 \%$ 


\section{2,4-Dinitrophenylhydrazine (DNPH) assay}

DNPH (2,4-dinitrophenylhydrazine) is a reagent used to detect the carbonyl of ketone or aldehyde functional groups. In this study, the formation of red dinitrophenylhydrazone with CPMK and DNPH substrates can be regarded as a positive result. First, DNPH was dissolved at $20 \mathrm{mM}$ in ethanol containing $3 \%$ sulfuric acid and stored in darkness. Then, the chromogenic reaction was performed by addition of $100 \mu \mathrm{L}$ of the DNPH solution into $100 \mu \mathrm{L}$ of effluent (after packed bed reactor). After standing for $15 \mathrm{~min}$ at $30^{\circ} \mathrm{C}, 1 \mathrm{~mL}$ of $\mathrm{KOH}(0.5 \mathrm{M})$ was added, and the absorbance of the solution was determined at $500 \mathrm{~nm}$ by a microplate reader (Biotek, USA). Samples without CPMK were used as the control.

\section{Bio-reduction catalyzed by immobilized enzyme}

\section{Optimal pH and temperature}

Substrate conversion was performed in a 5-mL mixture containing Mu-S5 and BmGDH (2 $\mathrm{U}$ each), $50 \mathrm{mM} \mathrm{CPMK}$, and $50 \mathrm{mM}$ glucose. The optimal $\mathrm{pH}$ of the reaction was determined by measuring the substrate conversion in the following buffers: sodium citrate-citric acid buffer (SCC buffer, $\mathrm{pH}$ 5.0-6.0, $100 \mathrm{mM}$ ), sodium phosphate buffer (pH 6.0-8.0, $100 \mathrm{mM}$ ), and Tris- $\mathrm{HCl}(\mathrm{pH} 7.5-9.0,100 \mathrm{mM})$. The optimal temperature was determined by measuring substrate conversion at $25-40^{\circ} \mathrm{C}$.

\section{Optimal ratio of $\mathrm{Mu}-\mathrm{S} 5$ and $\mathrm{BmGDH}$}

A total dry mass of $2 \mathrm{mg}$ purified Mu-S5 and $\mathrm{BmGDH}$ were mixed at activity ratios of 10:1 to $1: 10$. The reaction mixture containing $100 \mathrm{mM} \mathrm{CPMK}, 100 \mathrm{mM}$ glucose, 
premixed solutions of Mu-S5 and $\mathrm{BmGDH}$, and $100 \mathrm{mM}$ Tris- $\mathrm{HCl}(\mathrm{pH} 7.5)$ in a final volume of $5 \mathrm{~mL}$, was conducted at $30^{\circ} \mathrm{C}$ for $30 \mathrm{~min}$. The substrate conversion was analyzed by HPLC.

\section{Effect of various co-solvents}

In the pre-experiments, $10 \mathrm{mM} \mathrm{CPMK} \mathrm{was} \mathrm{dissolved} \mathrm{in} \mathrm{different} \mathrm{co-solvents.} \mathrm{A} \mathrm{mother}$ solution of CPMK (1.0 M) was prepared in ethanol by heating. Different amounts of co-solvents were added into $10 \mu \mathrm{L}$ of the CPMK mother solution $(1.0 \mathrm{M})$, then different volumes of water were added to a final volume of $1 \mathrm{~mL}$ (Table S7 \& S8). According to preliminary results, $5 \%$ Tween $80,2.5 \%$ Triton X-100, and $20-40 \mathrm{mM} \mathrm{HP-} \beta$-CD were tested as co-solvents. Substrate conversion was performed in a $5-\mathrm{mL}$ mixture containing $0.2 \mathrm{U}$ of Mu-S5 and $0.1 \mathrm{U}$ of $\mathrm{BmGDH}, 10 \mathrm{mM}$ glucose, and $10 \mathrm{mM} \mathrm{CPMK}$. The substrate conversion was analyzed by HPLC.

\section{Extraction with macroporous resins}

\section{Static adsorption/desorption rate of macroporous resins toward CPMA}

Adsorption rate: Substrate CPMK in Solution B was replaced with the product $(S)$ CPMA to prepare Solution C. A mass of $0.5 \mathrm{~g}$ resin D101 or XDA-1 was added into 10 $\mathrm{mL}$ of Solution $\mathrm{C}$; the adsorption process was then carried out at $30^{\circ} \mathrm{C}$ and $150 \mathrm{rpm}$ for $4 \mathrm{~h}$, and the non-adsorbed $(S)$-CPMA was analyzed by HPLC.

Adsorption rate $=\frac{\text { Initial concentration-Residual concentration }}{\text { Initial concentration }} \times 100 \%$

Desorption rate: The $0.5 \mathrm{~g}$ masses of resin D101 or XDA-1 that had adsorbed $(S)$ CPMA were washed with water and filtered on a Buchner funnel. A volume of $10 \mathrm{~mL}$ 
ethanol or ethyl acetate was added, and the desorption process was carried out at $30^{\circ} \mathrm{C}$ and $150 \mathrm{rpm}$ for $4 \mathrm{~h}$. The concentration of $(S)$-CPMA in the desorbing agent was analyzed by HPLC.

Desorption rate $=\frac{\text { Concentration in the desorbing agent }}{\text { Initial concentration }} \times 100 \%$

\section{Adsorption capacity of macroporous resins toward NADP ${ }^{+}$}

A mass of $0.5 \mathrm{~g}$ resin D101 or XDA-1 was added to $10 \mathrm{~mL}$ of solution containing 10 $\mathrm{mM} \mathrm{NADP}{ }^{+}$. The adsorption process was carried out at $30^{\circ} \mathrm{C}$ and $150 \mathrm{rpm}$ for $4 \mathrm{~h}$ and the absorption capacity was determined using an EnzyChrom NADP ${ }^{+} / \mathrm{NADPH}$ assay kit from BioAssay Systems (Hayward, CA).

\section{Continuous flow reaction in a 10-mL PBR}

A 12-mL polypropylene column was packed with $10 \mathrm{~mL}$ of Ni-NTA Cerose to prepare a PBR. A total of $200 \mathrm{mg}$ of purified enzyme was loaded (141.1 mg Mu-S5 (940 U) and $58.9 \mathrm{mg} \mathrm{BmGDH}(470 \mathrm{U})$ ), and the enzyme loading was $20 \mathrm{mg}$ protein/mL Ni-NTA Cerose (eg. $16.7 \mathrm{mg}$ protein/g Ni-NTA Cerose). For operational convenience, 50 $\mathrm{mg} / \mathrm{mL}$ solutions of both Mu-S5 and $\mathrm{Bm} \mathrm{GDH}$ were prepared, corresponding to $5.08 \mathrm{~mL}$ and $1.99 \mathrm{~mL}$ loading volumes, respectively. A peristaltic pump was used to pump Solution B through the PBR at $5 \mathrm{~mL} / \mathrm{min}$. A glass column filled with $28 \mathrm{~g}(40 \mathrm{~mL})$ of resin D101 was connected to the PBR to extract CPMA from the effluent of the PBR. A total of $4 \mathrm{~L}$ of reaction solution was prepared as described above. To ensure the continuity of the process, the $4 \mathrm{~L}$ initial reaction solution was divided into two portions (2 $\mathrm{L}$ each) for rotation. According to the dynamic adsorption capacity of macroporous 
resin D101, 5 columns (40 $\mathrm{mL})$ filled with D101 were required to adsorb $(S)$-CPMA from $2 \mathrm{~L}$ of effluent. In this study, a fresh D101 column was changed every $80 \mathrm{~min}$. Notably, D101 resin is reproducible and recyclable. After 400 min, 2 L of effluent solution was collected, and $2 \mathrm{~mL}$ CPMK solution (dissolved in ethanol at $1 \mathrm{M}$ ) was added as reaction solution for recycling. Meanwhile, the resin 101 that adsorbed $(S)$ CPMA in each column was collected and filtered with a Buchner funnel. A double volume $(80 \mathrm{~mL})$ of ethyl acetate was added, and the desorption process was carried out at $30^{\circ} \mathrm{C}$ and $150 \mathrm{rpm}$ for $4 \mathrm{~h}$. The product $(S)$-CPMA was concentrated by rotary evaporation.

The space-time-yield (STY) was defined as the mass of (S)-CPMA produced per milliliter of PBR enzyme per day.

$\mathrm{STY}=\frac{\text { Amount of }(S)-\mathrm{CPMA}(\mathrm{g})}{\text { Volume of PBR }(\mathrm{L}) \times \text { Reaction time }(\mathrm{d})}$

\section{Treatment of column packing for recovery and reuse}

After each batch process, the immobilized Ni-NTA Cerose was washed with 10 column volumes of $50 \mathrm{mM}$ EDTA and water sequentially. After 30 min incubation with a solution of $100 \mathrm{mM} \mathrm{NiSO}_{4}$, the column was washed with 10 column volumes of water, and then reused for the next batch.

For the product adsorbent column, $(S)$-CPMA was collected by soaking with ethyl acetate, then the D101 macroporous resin was sequentially washed using a Buchner funnel with 2 column volumes of the following: a solution containing $95 \%$ ethanol, water, and $3 \% \mathrm{HCl}$; water (rinsed to neutral); a $3 \% \mathrm{NaOH}$ solution; water (rinsed to 
neutral).

\section{Results and discussion}

\section{Device for enzyme immobilization and product recovery}

For continuous synthesis of (S)-CPMA, a prototype combined device consisting of four main parts was designed (Fig. 1), including a bottle of flow reaction solution (containing dissolved CPMK, NADP ${ }^{+}$, and glucose), a PBR containing Ni-NTA Cerose with immobilized Mu-S5 and $B m \mathrm{GDH}$, a macroporous resin column for adsorbing hydrophobic products, and a beaker for effluent recovery. When the reaction solution flowed through the PBR, the ketone substrate CPMK was reduced into the corresponding chiral alcohol $(S)$-CPMA. After that, the hydrophobic $(S)$-CPMA would be adsorbed by the resin column, whereas the effluent solution containing residual water-soluble $\mathrm{NAD}(\mathrm{P}) \mathrm{H} / \mathrm{NAD}(\mathrm{P})^{+}$and by-product gluconate would be collected for recovery. After replenishing CPMK and glucose, the effluent solution could be reused as reaction solution. The post-column samples of the PBR and the resin column were determined by using a previously established DNPH assay [37] to ensure complete bioreduction and adsorption. When the resin column reached saturation, it could easily be replaced with a new one, and the adsorbed $(S)$-CPMA could be separated from the resin by static or dynamic elution. This operation mode not only avoids the emulsification issue caused by extraction with organic solvents in biocatalytic reaction system, but also allows for the reuse of expensive cofactors. Moreover, Ni-NTA Cerose could be recycled and reused by treatment with EDTA and $\mathrm{NiSO}_{4}$ solutions after each batch. For 
the product adsorbent column, D101 macroporous resin is also recyclable and can be reused by treatment with dilute acid and alkali solutions. The whole process is simple and easy to operate with low material and downstream costs. Optimization of reaction conditions was performed to verify the feasibility of the continuous reaction process.

\section{Screening of supports for the immobilization of Mu-S5 and $\mathrm{BmGDH}$}

Immobilized metal affinity chromatography (IMAC) is commonly used for His-tagged protein purification and can also be applied to the immobilization of enzymes [25]. Herein, a commercially available NTA Cerose was chosen as the immobilization carrier material. Compared with the NTA agarose $(0.05 \mathrm{Mpa} / \mathrm{cm})$ commonly used in purification, NTA Cerose $(1 \mathrm{Mpa} / \mathrm{cm})$ possesses a stronger stability under system pressure and can withstand relatively higher flow rates. $\mathrm{Ni}^{2+}$ and $\mathrm{Mn}^{2+}$ were selected due to their positive effects on the catalytic activity of Mu-S5 (104\% for $\mathrm{Ni}^{2+}$ and $116 \%$ for $\mathrm{Mn}^{2+}$ ) (Fig. 2A). After immobilization, protein loading per gram carrier was calculated to be $61.9 \mathrm{mg}$ for Ni-NTA Cerose and $42.2 \mathrm{mg}$ for Mn-NTA Cerose (Table S2). Additionally, Ni-NTA Cerose and Mn-NTA Cerose maintained 58.0\% and $66.4 \%$ relative catalytic activity compare with that of free enzyme in shake flasks, respectively (Table S6).

The dilution ratio was defined as the reactor volume divided by the volumetric flow rate of substrate, and it was used to evaluate the reactor performance. For Ni-NTA Cerose immobilized Mu-S5, the substrate conversion remained over 99\% with increased substrate flow rate, whereas a consistent decline of conversion was observed 
for Mn-NTA Cerose. The conversion decreased to less than $50 \%$ at a flow rate of 1 $\mathrm{mL} / \mathrm{min}$ for Mn-NTA (Fig. 2B). Due to the larger ionic radius of the $\mathrm{Mn}^{2+}$ ion $(91 \mathrm{~nm}$ ) compared to the $\mathrm{Ni}^{2+}$ ion $(73 \mathrm{~nm})$, the metal coordination bond strength of $\mathrm{Ni}^{2+}$ is stronger than that of $\mathrm{Mn}^{2+}$. This difference in coordination bond strength is likely responsible for the poor performance of Mn-NTA. Notably, no protein leaching was detected at dilution rates of $0.2-1.0 \mathrm{~min}^{-1}$ as evaluated by a Bradford assay. Therefore, insufficient enzyme immobilized on Mn-NTA is likely responsible for the low conversion. To further reduce the cost, a cheaper chelating resin IRC-748 was functionalized with $\mathrm{Ni}^{2+}$ and employed for enzyme immobilization. However, activity above $85 \%$ was lost after immobilization due to the poor biocompatibility of the resin. Therefore, Ni-NTA Cerose was selected for protein immobilization.

\section{Comparison of $6 \times$ His-tag and Heli-tag in protein immobilization}

In addition to the $6 \times$ His- tag, the Heli-tag fusion peptide with higher affinity was attempted for immobilization [28, 29]. Since the C-terminal portion of Mu-S5 is buried and solvent inaccessible, the Heli-tag was fused to the N-terminal of Mu-S5.

The affinity of $6 \times$ His- and Heli-tagged Mu-S5 with Ni-NTA was compared under the same elution conditions (Fig. 3). The two fused Mu-S5s showed similar solubility as confirmed by SDS-PAGE. Both fusion proteins were barely detected in the flowthrough (lane 3). The majority of the 6xHis-tag fused Mu-S5 eluted at $100 \mathrm{mM}$ imidazole, and some was eluted at $50 \mathrm{mM}$ imidazole. (Fig. 3B). In contrast, almost all of the Heli-tag fused Mu-S5 was eluted at 20-50 mM imidazole (Fig. 3 A). After elution 
with $50 \mathrm{mM}$ imidazole, over $95 \%$ of enzymatic activity was lost with the of Heli-tag fused Mu-S5, whereas only 3.9\% activity loss was observed with the $6 \times$ His-tag fused Mu-S5 (Table S9). It is speculated that the Heli-tag may not be fully exposed on the surface of Mu-S5, which may affect the structure and conformation of the protein [40]. Collectively, the Heli-tag that has been proven to be effective in D-amino acid oxidase immobilization [30] is not applicable for Mu-S5, and the $6 \times$ His-tag was used for enzyme immobilization for further study.

\section{Optimization of reaction conditions of PBR}

The reaction conditions were optimized to obtain improved catalytic performance. The $\mathrm{pH}$, temperature, ratio of $\mathrm{Mu}-\mathrm{S} 5 / \mathrm{Bm} \mathrm{GDH}$, and co-solvent were optimized in shake flasks, and the dilution rate was determined in a PBR. As shown in Fig. 4A, Mu-S5 showed optimal activity at $\mathrm{pH} 7.5$ in Tris- $\mathrm{HCl}$ buffer. The optimal temperature of the reaction was $30^{\circ} \mathrm{C}$ (Fig. 4B), and the reaction can be conveniently performed at room temperature. Under the optimized $\mathrm{pH}$ and temperature, the highest conversion (75.1\%) was achieved using immobilized $\mathrm{Mu}-\mathrm{S} 5 / \mathrm{Bm} \mathrm{GDH}$ at an activity ratio of 2:1 (Fig. 4C), which may be related to the addition of an equal amount of glucose as co-substrate. As there were not significant differences in the large-scale fermentation costs between MuS5 and $B m$ GDH (Table S1), the optimized activity ratio of 2:1 is acceptable.

Additionally, an aqueous solution of the insoluble substrate CPMK should be prepared for the continuous process. Several commonly used dispersants were screened, and a $10 \mathrm{mM}$ aqueous solution of CPMK could be obtained when supplemented with $5 \%$ 

in preliminary experiments (Table $\mathbf{S 7} \boldsymbol{\&}$ S8). Fig. 4D shows the effect of co-solvents on catalytic activity of immobilized $\mathrm{Mu}-\mathrm{S} 5$, and a reaction system with the addition of $20 \%$ ethanol served as a control. A decrease in substrate conversions was observed when using Tween 80 and Triton X-100 as co-solvents, and this may be attributed to the disrupted protein conformation that results from the interactions between the nonionic surfactant and the hydrophobic region of the enzyme. Surprisingly, HP- $\beta$-CD not only improved the substrate solubility but also exhibited excellent biocompatibility. Benefiting from the hydrophilic exterior and hydrophobic interior structure of HP- $\beta$ $\mathrm{CD}$, mass transfer was improved, and almost complete conversions were achieved with the addition of $20-40 \mathrm{mM}$ HP- $\beta$-CD, whereas only $76.4 \%$ conversion was observed in the control reaction ( $20 \%$ ethanol). Finally, the dilution rate of $10 \mathrm{~mL} \operatorname{PBR}(\Phi=1.6 \mathrm{~cm}$, $h=5.5 \mathrm{~cm}$ ) was determined under the optimized reaction conditions. As shown in Fig. $\mathbf{4 E}$, the substrate conversion began to decrease when the volumetric flow rate of CPMK exceeded $6 \mathrm{~mL} / \mathrm{min}$, and only $93.1 \%$ conversion was detected at an increased flow rate of $10 \mathrm{~mL} / \mathrm{min}$ without protein leaching. Considering possible damage to the immobilized materials and enzymes caused by the long-term continuous reaction, a volumetric flow rate of $5 \mathrm{~mL} / \mathrm{min}$ was chosen.

\section{Comparison of properties of D101 and XDA-1}

Macroporous resins possess stable physical and chemical properties, and can be classified into three types: polar, non-polar, and weakly polar. According to the design, 
the hydrophobic diaryl alcohol product is expected to be adsorbed whereas the watersoluble cofactor should be recycled and reused for consecutive reaction cycles. Therefore, two commonly used non-polar macroporous resins D101 and XDA-1 were selected for $(S)$-CPMA enrichment (Table S10). The adsorption rate is an important index to evaluate the adsorption performance of macroporous resins. As shown in Table $1 \&$ S11, the two resins maintained almost the same adsorption capacity toward the product $(S)$-CPMA. Resin XDA-1 with a larger surface area exhibited more than a $90 \%$ static adsorption rate. The desorption rate of the two resins toward $(S)$-CPMA was also compared (Table S12). Firstly, different proportions of recommended aqueous-ethanol were used as washing solutions, however, only about $20 \%$ of the product could be eluted even when pure ethanol (100\%) was used. Then, ethyl acetate with lower polarity was tested, and the desorption rate increased rapidly. In the case of D101, more than $95 \%$ of CPMA could be eluted with the addition of ethyl acetate, whereas only $82.6 \%$ of CPMA could be eluted when XDA-1 was selected for extraction. Afterward, the residual $\mathrm{NADP}^{+}$concentration was measured using an $\mathrm{NADP}^{+} / \mathrm{NADPH}$ assay kit to evaluate whether the selected resin could be used for coenzyme recycling. The results showed that neither D101 nor XDA-1 could adsorb NADP ${ }^{+}$(Table S13, Fig S4). Thus, D101 was selected as the supporting material in the extraction column due to the higher desorption rate. Using a $40 \mathrm{~mL}$ column $(\Phi=1.6 \mathrm{~cm}, h=20 \mathrm{~cm})$ filled with $28 \mathrm{~g}$ of D101 resin, fractions were collected sequentially every $10 \mathrm{~mL}$, and a trace amount of $(S)$ CPMA was detected in the $47^{\text {th }}$ sample. The dynamic adsorption capacity of D101 was calculated to be $36.3 \mathrm{mg} / \mathrm{g}$, which is roughly equal to its static adsorption capacity (38.6 
$\mathrm{mg} / \mathrm{g})$.

\section{Asymmetric synthesis and in situ extraction of (S)-CPMA in a continuous device}

Asymmetric synthesis of $(S)$-CPMA was carried out under optimized immobilization and reaction conditions. Fig. 5 shows the conversion ratio of CPMK catalyzed by immobilized $\mathrm{Mu}-\mathrm{S} 5 / \mathrm{Bm} \mathrm{GDH}$ in a $10-\mathrm{mL}$ PBR. A complete conversion of CPMK was observed in the first 3 days followed by a gradual decline. When the reaction proceeded to day 4, an obvious red-brown color formed in DNPH assay, indicating an incomplete conversion of the ketone substrate. On day 7 , only $54.3 \%$ conversion was observed by HPLC, and conversion continued to decreased sharply to $22.5 \%$ on day 8 . In view of the negligible effect of the His-tag on protein structure, the insufficient stability of the Mu-S5 (half-life of $152 \mathrm{~h}$ at $30^{\circ} \mathrm{C}$, Fig. S5) might be responsible for the decreased substrate conversion after day 3. Finally, the STY was calculated to be $1,560 \mathrm{~g} /(\mathrm{L} \cdot \mathrm{d})$ based on data from day 1 to 3 . A total volume of $4 \mathrm{~L}$ initial reaction solution was recycled up to 6 times. After 400 min of reaction, the D101 resin in the first 5 adsorption columns was collected, and a total of $3.63 \mathrm{~g}(S)$-CPMA with $84 \%$ isolated yield was obtained by ethyl acetate extraction.

Peschke et al. reported an emerging co-immobilization approach using Spy-tag and Spycatcher fusion enzymes [32]. However, hydrogels self-assembled from free enzymes alone are mechanically fragile, which limit the operation strength and flow rate of continuous reactions. In comparison, immobilized $\mathrm{KpADH} \mathrm{Mu}-\mathrm{S} 5$ and $\mathrm{BmGDH}$ maintained excellent catalytic activity and operational stability under a $5 \mathrm{~min}^{-1}$ dilution 
rate during the first 3 days of the reaction. In a study by Dall'Oglio and coworkers, KRED1-Pglu and GDH were covalently bound to aldehyde activated agarose [31]. Although the stability and solvent tolerance were improved, alkaline operating conditions $(\mathrm{pH} \geqslant 10)$ pose a challenge to the catalytic activity of enzymes. For example, Tt-ADH2 and formate dehydrogenase (FDH) had to be immobilized by covalent binding and ionic adsorption, respectively, due to the inactivation of FDH after aldehyde immobilization [35]. In our study, ADH and GDH were both coordination bound to Ni-NTA Cerose, and over $60 \%$ of catalytic activity could be maintained under near-neutral conditions ( $\mathrm{pH}$ 7.5). Using commercially available enzyme membrane reactor, $(R)$-2-octanol could be continuously synthesized by co-immobilized $\mathrm{LbADH}$ and GDH, and produced a fairly high STY of $454 \mathrm{~g} /(\mathrm{L} \cdot \mathrm{d})$. Additionally, product separation and cofactor recycling were achieved by supercritical carbon dioxide $\left(\mathrm{scCO}_{2}\right)$ extraction [41] (Table 2).

In our study, the macroporous resin adsorption strategy with low equipment requirements was facilely used for product recovery, and in the subsequent resin extraction step, much less organic solvent was used than in traditional liquid-liquid extractions. Additionally, emulsification caused by proteins in free-enzyme systems was completely avoided, and a satisfactory yield was obtained by the simple operations of soaking and rotary evaporation.

\section{Conclusions}

Continuous flow biocatalysis can improve the overall reaction process by protecting 
475 fragile enzymes from mechanical stirring or agitation, as well as simplifying the 476 downstream product isolation and treatment. Herein, a 6xHis-tag fused Mu-S5 and $477 B m$ GDH were co-immobilized on Ni-NTA Cerose to construct a PBR for continuous 478 asymmetric synthesis of $(S)$-CPMA. As a support material for enzyme immobilization, 479 the commercially available Ni-NTA Cerose is recyclable in process operation, 480 Furthermore, the D101 macroporous resin column was used after the PBR to adsorb the (S)-CPMA product specifically, and recycling and reuse of the reaction solution

containing hydrophilic NADP ${ }^{+} / \mathrm{NADPH}$ was easily achieved. During $400 \mathrm{~min}$ of flow reaction, a $4 \mathrm{~L}$ initial reaction solution could be recycled up to 6 times, demonstrating the feasibility of reducing the cost of cofactors. Additionally, the $(S)$-CPMA product was enriched on the D101 resin and could be separated conveniently and effectively by soaking in ethyl acetate. In summary, the designed continuous biocatalytic process using coupled PBR and in situ product recovery could be potentially applied in preparation of chiral alcohols. This continuous flow biocatalysis system is especially suitable for enzymatic reactions involving cofactor recycling and substrate/product inhibitory issues.

\section{Acknowledgements}

This work was supported by National Key R\&D Program [2018YFA0901700], National Natural Science Foundation of China [21907040, 21776112, 22077054], China Postdoctoral Science Foundation [2019M651703], National First-Class Discipline Program of Light Industry Technology and Engineering [LITE2018-07], 


\section{Authors' contributions}

500 Jieyu Zhou: Conceptualization, Investigation, Methodology, Writing-original draft.

501 Yanfei Wu: Data curation. Qingye Zhang: Data curation, Formal analysis. Guochao

502 Xu: Writing-review \& editing. Ye Ni: Supervision, Writing-review \& editing, Project

503 administration, Funding acquisition.

504

505 Compliance with Ethical Standards

506 Competing Interests The authors declare that they have no known competing

507 financial interests or personal relationships that could have appeared to influence the 508 work reported in this paper

509

510 Supplementary

511 Supplementary material related to this article can be found in the online version.

512 


\section{References}

1. Britton, J., Majumdar, S. and Weiss, G.A. (2018) Chem. Soc. Rev. 47, 58915918.

2. Adamo, A., Beingessner, R.L., Behnam, M., Chen, J., Jamison, T.F., Jensen, K.F., Monbaliu, J.M., Myerson, A.S., Revalor, E.M., Snead, D.R., Stelzer, T., Weeranoppanant, N., Wong, S.Y. and Zhang, P. (2016) Science 352, 54-61.

3. Webb, D. and Jamison, T.F. (2010) Chem. Sci. 1, 675-680.

4. Cuong, N.P., Lee, W., Oh, I., Thuy, N.M., Kim, D., Park, J. and Park, K. (2016) Process Biochem. 51, 282-287.

5. Cimporescu, A., Todea, A., Badea, V., Paul, C. and Peter, F. (2016) Process Biochem. 51, 2076-2083.

6. Jia, C., Wang, H., Zhang, W., Zhang, X. and Feng, B. (2018) Process Biochem. $66,28-32$.

7. de Oliveira Lopes, R., Ribeiro, J.B., Silva De Miranda, A., Vieira Da Silva, G.V., Miranda, L.S.M., Ramos Leal, I.C. and Mendonça Alves De Souza, R.O. (2014). Tetrahedron 70, 3239-3242.

8. Tamborini, L., Romano, D., Pinto, A., Contente, M., Iannuzzi, M.C., Conti, P. and Molinari, F. (2013). Tetrahedron Lett. 54, 6090-6093.

9. J. Döbber, T.G.H.O. (2018). Green Chem. 20, 544-552.

10. Xiao, M., Qi, C. and Obbard, J.P. (2011) Bioenergy 3, 293-298.

11. Tan, A.W., Fischbach, M., Huebner, H., Buchholz, R., Hummel, W., Daussmann, T., Wandrey, C. and Liese, A. (2006). Appl. Microbiol. Biotechnol. 71, 289-93. 
535

536

537

538

539

540

541

542

543

544

545

546

547

548

549

550

551

552

553

554

555

556

12. Thompson, M.P., Peñafiel, I., Cosgrove, S.C. and Turner, N.J. (2018). Org. Process Res. Dev. 23, 9-18.

13. Li, F., Zheng, Y., Li, H., Chen, F., Yu, H. and Xu, J. (2019). Tetrahedron 75, 1706-1710.

14. Orrego, A.H., López-Gallego, F., Espaillat, A., Cava, F., M., J. and A, G.A.A.J. (2018). ChemCatChem 10, 3002-3011.

15. García-García, P., Rocha-Martin, J., Fernandez-Lorente, G. and Guisan, J.M. (2018) Enzyme Microb. Tech. 115, 73-80.

16. Arana-Pena, S., Carballares, D., Morellon-Sterlling, R., Berenguer-Murcia, A., Alcantara, A.R., Rodrigues, R.C. and Fernandez-Lafuente, R. (2020). Biotechnol. Adv. 107584.

17. Rocha-Martín, J., Rivas, B.D.L., Muñoz, R., Guisán, J.M. and López-Gallego, F. (2012). ChemCatChem 4, 1279-1288.

18. Trobo-Maseda, L., Orrego, A.H., Guisan, J.M. and Rocha-Martin, J. (2020). Int. J. Biol. Macromol. 157, 510-521.

19. Hearon, J.Z., Sundberg, L., and MalmstrOm, B.G. (1975). Nature 258, 598-599.

20. Planchestainer, M., Contente, M.L., Cassidy, J., Molinari, F., Tamborini, L. and Paradisi, F. (2017) Green Chem. 19, 372-375.

21. Liu, J., Pang, B.Q.W., Adams, J.P., Snajdrova, R. and Li, Z. (2017). ChemCatChem 9, 425-431.

22. Vahidi, A.K., Yang, Y., Ngo, T.P.N. and Li, Z. (2015). ACS Catal. 5, 3157-3161.

23. Yang, J., Ni, K., Wei, D. and Ren, Y. (2015). Biotechnol. Bioproc. E. 20, 901- 
558

559

560

561

562

563

564

565

566

567

568

569

570

571

572

573

574

575

576

577

578

24. Engelmark Cassimjee, K., Kadow, M., Wikmark, Y., Svedendahl Humble, M., Rothstein, M.L., Rothstein, D.M. and Bäckvall, J.E. (2014). Chem. Commun. 50, 9134.

25. Ueda, E.K.M., Gout, P.W. and Morganti, L. (2003). J. Chromatogr. A. 988, 1-23.

26. Chou, Y., Ko, C., Chen, L.O. and Shaw, C.Y. (2015). Molecules 20, 3744-3757.

27. Böhmer, W., Knaus, T. and Mutti, F.G. (2018). ChemCatChem 10, 731-735.

28. Melchers, K., Herrmann, L., Mauch, F., Bayle, D., Heuermann, D., Weitzenegger, T., Schuhmacher, A., Sachs, G., Haas, R., Bode, G., Bensch, K. and Schäfer, K.P. (1998). Acta. Physiol. Scand. Suppl. 643, 123-135.

29. Melchers, K., Weitzenegger, T., Buhmann, A., Steinhilber, W., Sachs, G. and Schafer, K.P. (1996). J. Biol. Chem. 271, 446-57.

30. Hou, J., Jin, Q., Du, J., Li, Q., Yuan, Q. and Yang, J. (2014). Bioproc. Biosyst. Eng. 37, 857-864.

31. Dall'Oglio, F., Contente, M.L., Conti, P., Molinari, F., Monfredi, D., Pinto, A., Romano, D., Ubiali, D., Tamborini, L. and Serra, I. (2017). Catal. Commun. 93, 29-32.

32. Peschke, T., Bitterwolf, P., Gallus, S., Hu, Y., Oelschlaeger, C., Willenbacher, N., Rabe, K.S. and Niemeyer, C.M. (2018). Angew. Chem., int. Edit. 57, 1702817032.

33. Fassouane, A., Laval, J.M., Moiroux, J. and Bourdillon, C. (1990). Biotechnol. Bioeng. 35, 935-939. 
579

580

581

582

583

584

585

586

587

588

589

590

591

592

593

594

34. Ruinatscha, R., Buehler, K. and Schmid, A. (2014). J. Mol. Catal. B-Enzym. 103, 100-105.

35. Velasco-Lozano, S., Benítez-Mateos, A.I. and López-Gallego, F. (2017). Angew. Chem., int. Edit. 56, 771-775.

36. Benítez-Mateos, A.I., San Sebastian, E., Ríos-Lombardía, N., Morís, F., González-Sabín, J. and López-Gallego, F. (2017). Chem-Eur. J. 23, 16843-16852.

37. Zhou, J., Xu, G., Han, R., Dong, J., Zhang, W., Zhang, R. and Ni, Y. (2016). Catal. Sci. Technol. 6, 6320-6327.

38. Zhou, J., Wang, Y., Xu, G., Wu, L., Han, R., Schwaneberg, U., Rao, Y., Zhao, Y., Zhou, J. and Ni, Y. (2018). J. Am. Chem. Soc. 140, 12645-12654.

39. Ni, Y., Zhou, J. and Sun, Z. (2012). Process Biochem. 47, 1042-1048.

40. Gaberc-Porekar, V. and Menart, V. (2001). J. Biochem. Biophys. Methods 49, $335-360$.

41. Kohlmann, C., Leuchs, S., Greiner, L. and Leitnera, W. (2011). Green Chem. 13, 1430-1437. 
595

596

597

598

599

600

601

602

603

604

605

606

607

608

609

610

611

612

613

614

615

616

\section{Table and Figure Legends}

Table 1. Comparison of properties of D101 and XDA-1 resins.

Table 2. Comparison of asymmetric reductions catalyzed by various alcohol

dehydrogenases (ADHs) and glucose dehydrogenases (GDHs)/formate

dehydrogenases (FDHs) in flow reactions.

Fig. 1. Continuous biosynthesis of (S)-(4-chlorophenyl)-(pyridin-2-yl) methanol ( $S$ CPMA) with immobilized Mu-S5 and BmGDH and in situ product recovery.

Fig. 2. Effect of metal ions on catalytic activity of Mu-S5 (A). Effect of dilution ratio on conversion ratio of $\mathrm{Ni}$-and $\mathrm{Mn}$-functionalized porous ceramic/agarose composite beads (Cerose) immobilized enzymes (B).

Fig. 3. SDS-PAGE of recombinant Mu-S5 fused with Heli-Tag (A) or 6×His Tag (B) eluted at different Imidazole Concentrations. (A) M: protein ladder; lane 1: supernatant of crude Heli-tag fused Mu-S5; lane 2: sediment of crude Heli-tag fused Mu-S5; lane 3: Flow-through of crude Heli-tag fused Mu-S5; lane 4-7: eluent from washing Heli-tag fused Mu-S5 with 20, 50, 100 and 300 mM imidazole, respectively; (B) M: protein ladder; lane 1: supernatant of crude 6×His-tag fused Mu-S5; lane 2: sediment of crude $6 \times$ His-tag fused Mu-S5; lane 3: Flow-through of crude $6 \times$ His-tag fused Mu-S5; lane 4-7: eluent from washing 6xHis-tag fused Mu-S5 with 20, 50, 100 and $300 \mathrm{mM}$ imidazole, respectively.

Fig. 4. Optimization of reaction catalyzed by immobilized Mu-S5 and BmGDH. (A) $\mathrm{pH}$; (B) temperature; (C) ratio of Mu-S5 and $\mathrm{BmGDH}$; (D) co-solvent; (E) flow rate optimum of (4-chlorophenyl)(pyridine-2-yl)ketone (CPMK) in a 10-mL Ni- 
617 functionalized porous ceramic/agarose composite beads (Ni-NTA Cerose) packed bed 618 reactor.

619 Fig. 5. Continuous production of $(S)$-(4-chlorophenyl)-(pyridin-2-yl) methanol (S620 CPMA) in a 10-mL packed bed reactor.

621 
622 Table 1.

\begin{tabular}{cccccc}
\hline Resin & $\begin{array}{c}\text { Constituent } \\
\text { materials }\end{array}$ & $\begin{array}{c}\text { Average } \\
\text { aperture size } \\
(\mathrm{nm})\end{array}$ & $\begin{array}{c}\text { Specific } \\
\text { surface area } \\
\left(\mathrm{m}^{2} / \mathrm{g}\right)\end{array}$ & $\begin{array}{c}\text { Static } \\
\text { adsorption } \\
\text { rate }(\%)\end{array}$ & $\begin{array}{c}\text { Desorption } \\
\text { rate } \\
(\%)\end{array}$ \\
\hline D101 & Polystyrene & $25-28$ & $480-520$ & $88.1 \pm 0.13$ & $96.1 \pm 0.22$ \\
XDA-1 & Polyacrylic acid & $85-89$ & $1000-1100$ & $91.3 \pm 0.08$ & $82.7 \pm 0.31$ \\
\hline
\end{tabular}

623 
Table 2.

\begin{tabular}{|c|c|c|c|c|c|}
\hline & This study & Peschke et al. [32] & Dall'Oglio et al.[31] & $\begin{array}{l}\text { Kohlmann } \\
\text { et al.[41] }\end{array}$ & $\begin{array}{c}\text { Velasco-Lozano et al } \\
\qquad[35]\end{array}$ \\
\hline Ketone reductase & $\begin{array}{c}\text { Mu-S5 from } \\
\text { Kluyveromyces } \\
\text { polyspora }\end{array}$ & $\begin{array}{l}\text { LbADH from } \\
\text { Lactobacillus } \\
\text { brevis }\end{array}$ & $\begin{array}{l}\text { KRED1-Pglu from } \\
\text { Pichia } \\
\text { glucozyma }\end{array}$ & $\begin{array}{l}\text { LbADH from } \\
\text { Lactobacillus } \\
\text { brevis }\end{array}$ & $\begin{array}{c}\text { Tt-ADH2 from Thermus } \\
\text { thermophilus }\end{array}$ \\
\hline Cofactor recycling & GDH & GDH & GDH & GDH & FDH \\
\hline Immobilized strategy & IMAC & Self-assembling; & Covalent binding & $\begin{array}{l}\text { Interception by semi- } \\
\text { permeable membrane }\end{array}$ & $\begin{array}{c}\text { Covalent binding \& ionic } \\
\text { adsorption }\end{array}$ \\
\hline Support material & Cerose & Hydrogel & $\begin{array}{c}\text { Aldehyde activated } \\
\text { agarose }\end{array}$ & $\begin{array}{l}\text { Enzyme membrane } \\
\text { reactor }\end{array}$ & $\begin{array}{c}\text { Aldehyde activated } \\
\text { agarose \& } \\
\text { polyethyleneimine } \\
\text { agarose }\end{array}$ \\
\hline Substrate & СРMK & 5-nitrononane-2,8-dione & $\begin{array}{c}\text { 1-phenylpropane-1,2-dio } \\
\text { ne }\end{array}$ & octan-2-one & $\begin{array}{l}\text { 2,2,2-trifluoro-1- } \\
\text { phenylethanone }\end{array}$ \\
\hline Conc.(mM) & 10 & 5.0 & 3.0 & 6.0 & 5.0 \\
\hline $\begin{array}{l}\text { Reactor volume } \\
\qquad(\mathrm{mL})\end{array}$ & 10 & 0.15 & 0.90 & 16 & 1.2 \\
\hline Flow rate $(\mathrm{mL} / \mathrm{min})$ & 5.0 & 0.010 & 0.050 & 0.10 & 0.050 \\
\hline $\operatorname{SYT}(g /(L \cdot d))$ & 1560 & $\approx 100$ & $4.4-81.5$ & 454.5 & 62.7 \\
\hline $\begin{array}{l}\text { In situ product } \\
\text { recovery }\end{array}$ & $\begin{array}{c}\text { Macroporous resins } \\
\text { adsprption }\end{array}$ & No & No & scCO2 extraction. & No \\
\hline
\end{tabular}


Replenishment of CPMK and glucose

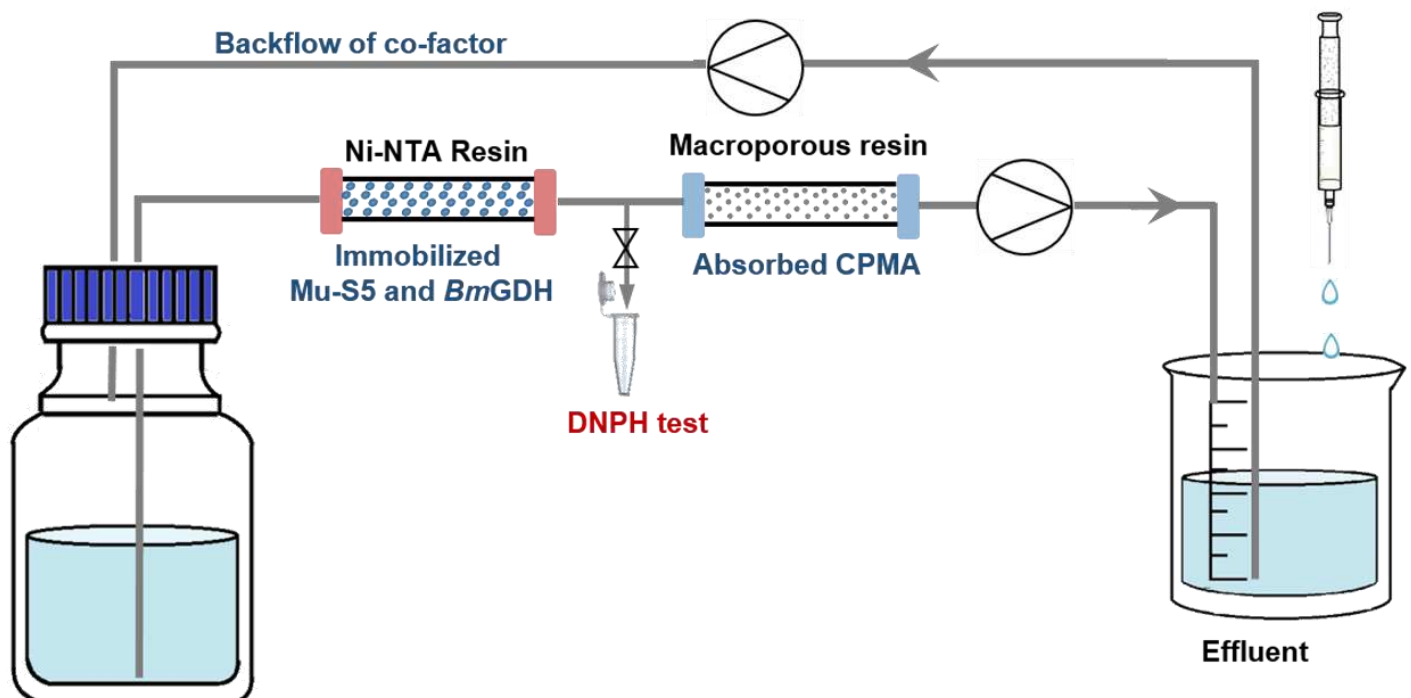

Solution of CPMK, 


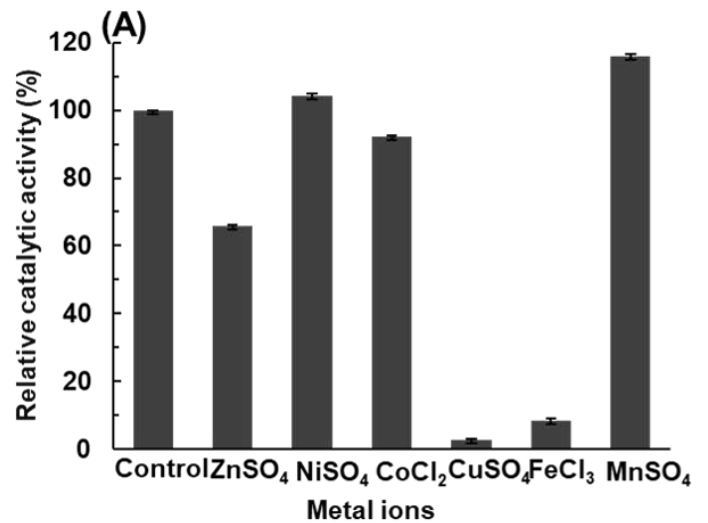

628

629
(B) $\quad$ Ni-NTA Cerose $\angle$ Mn-NTA Cerose

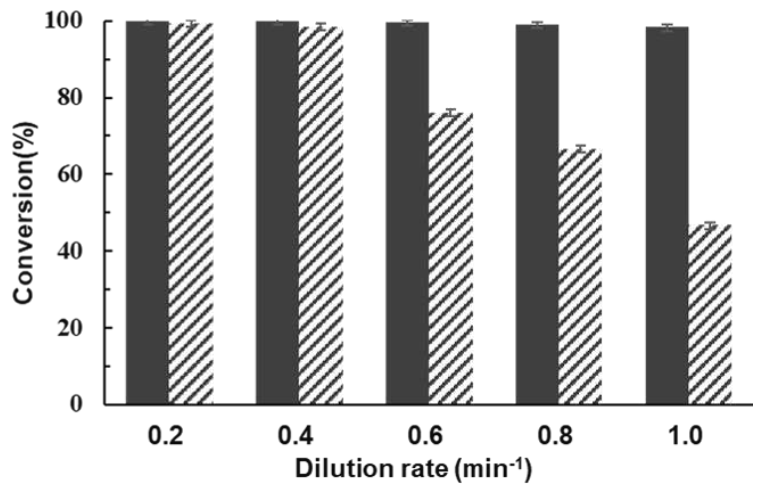

Fig. 2. 


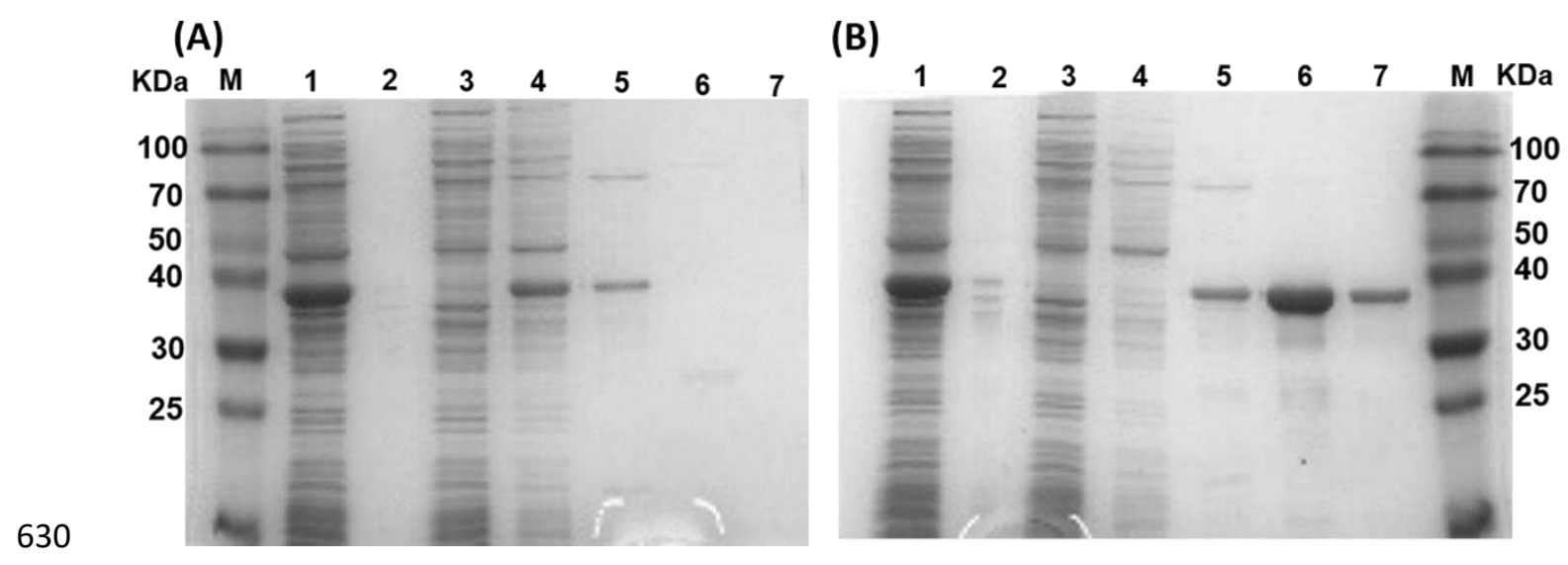

631

Fig. 3. 

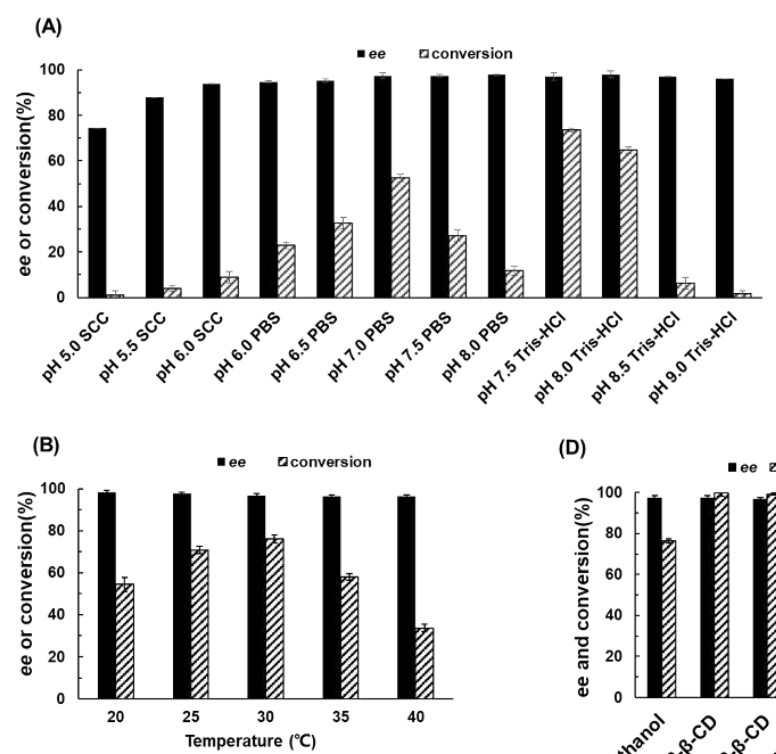

632

633

Fig. 4.
(C)
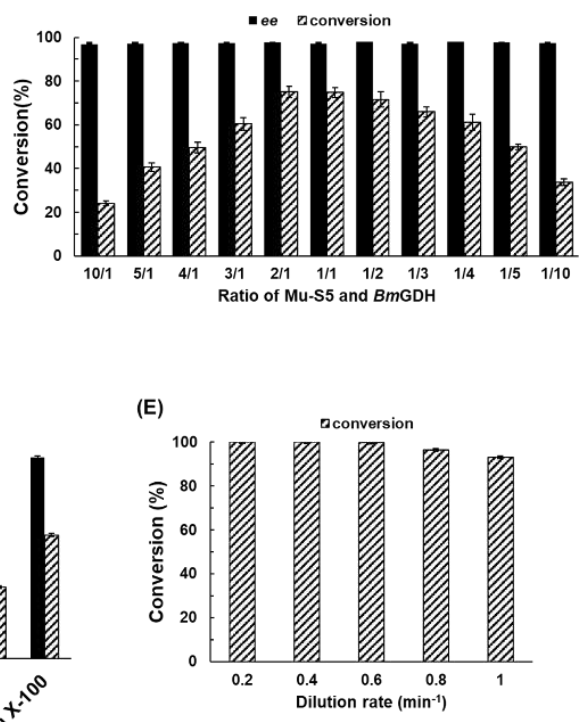

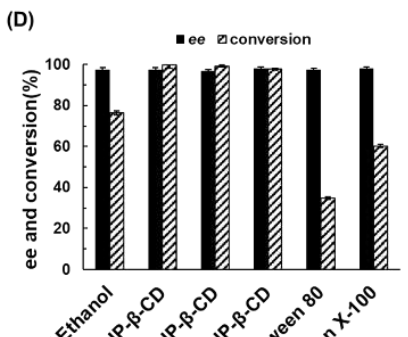

10

$\begin{array}{llr}0.4 & 0.6 & 0.8 \\ \text { Dilution rate } & \left(\mathrm{min}^{-1}\right)\end{array}$

$0^{0} 0^{\circ}$ a $0^{50}$ 


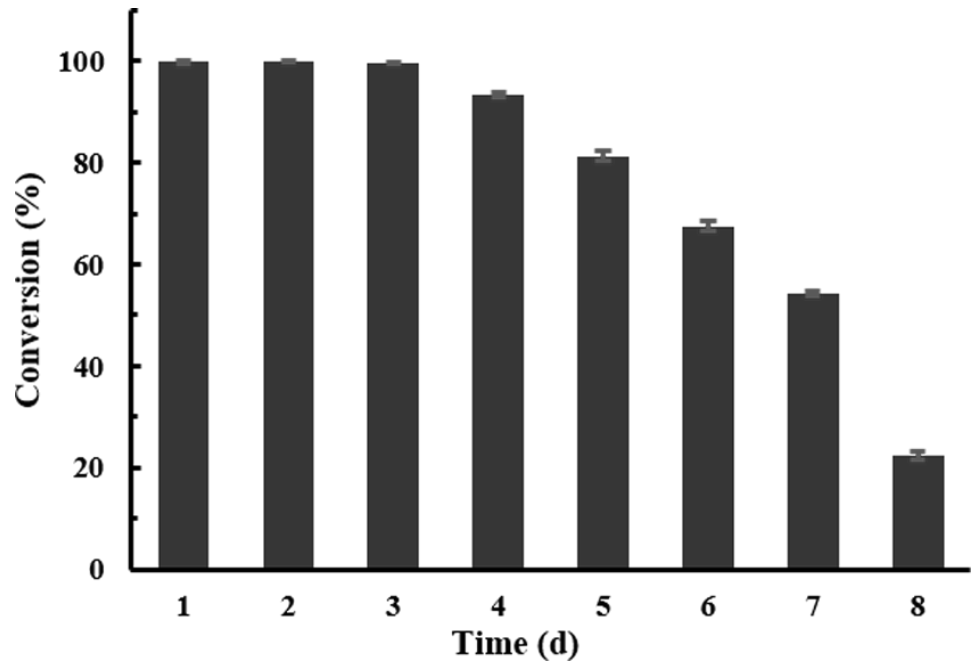

635

Fig. 5 
Replenishment of CPMK and glucose

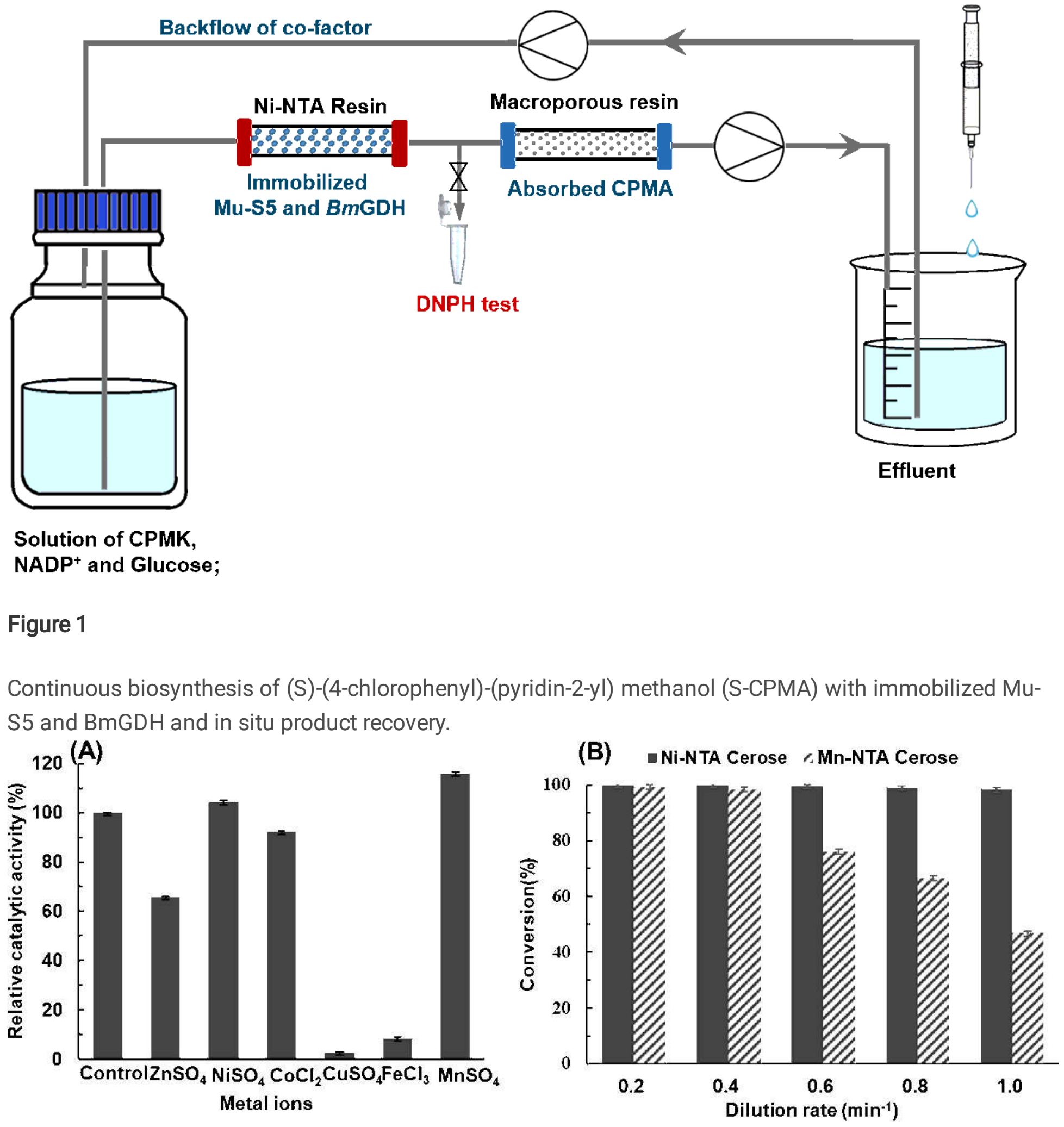

Figure 2 
Effect of metal ions on catalytic activity of Mu-S5 (A). Effect of dilution ratio on conversion ratio of Niand Mn-functionalized porous ceramic/agarose composite beads (Cerose) immobilized enzymes (B).

\section{(A) \\ (B)}

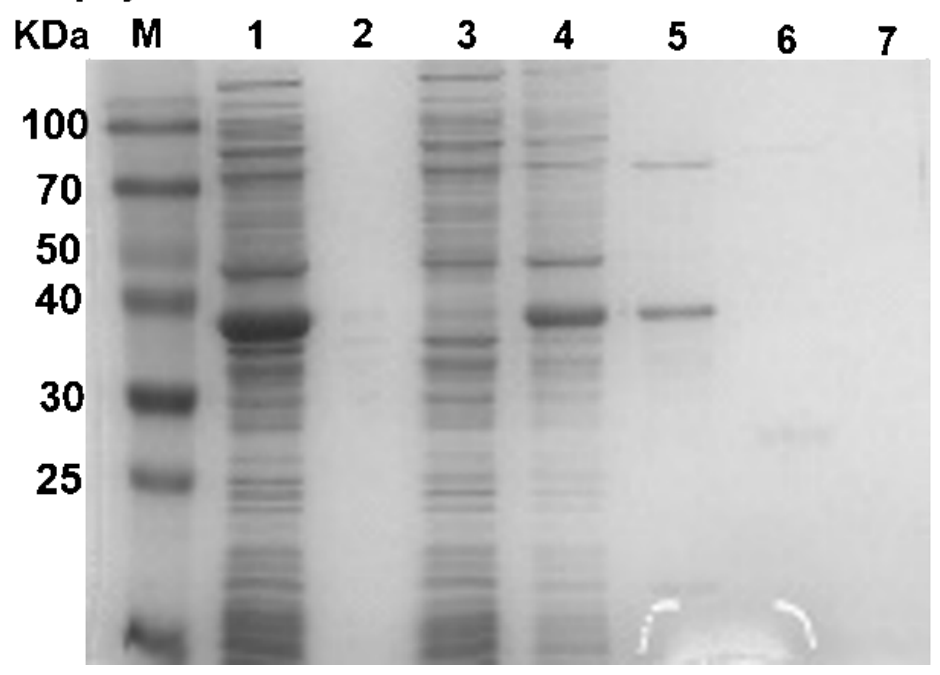

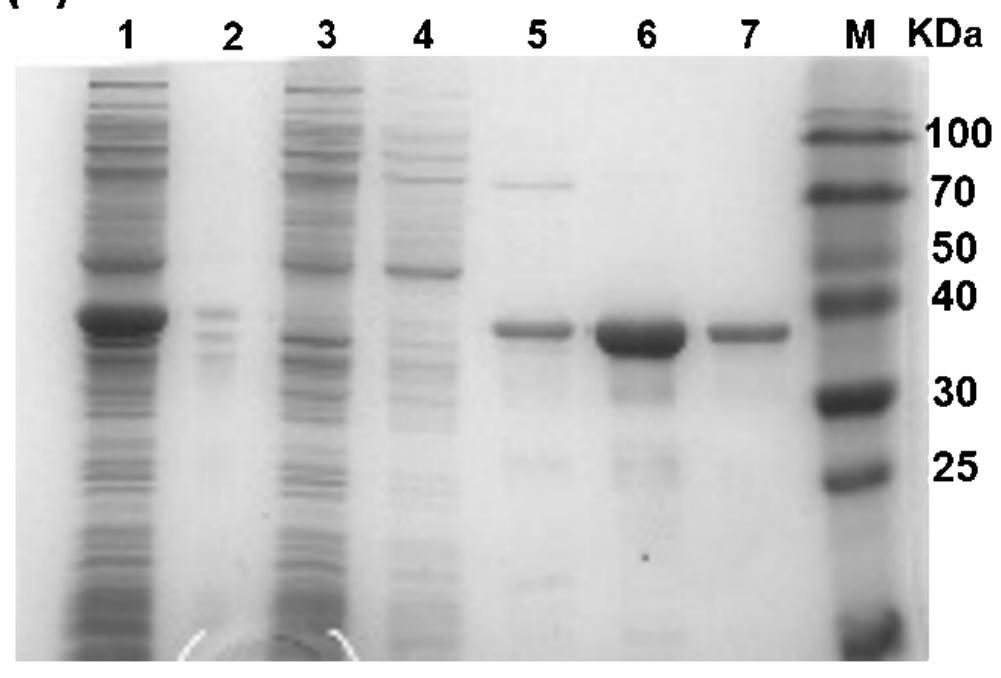

\section{Figure 3}

SDS-PAGE of recombinant Mu-S5 fused with Heli-Tag (A) or 6xHis Tag (B) eluted at different Imidazole Concentrations. (A) M: protein ladder; lane 1: supernatant of crude Heli-tag fused Mu-S5; lane 2: sediment of crude Heli-tag fused Mu-S5; lane 3: Flow-through of crude Heli-tag fused Mu-S5; lane 4-7: eluent from washing Heli-tag fused Mu-S5 with 20, 50, 100 and 300 mM imidazole, respectively; (B) M: protein ladder;

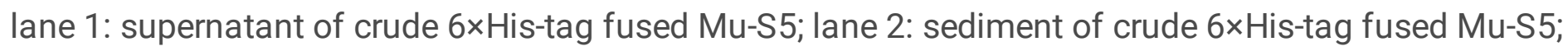
lane 3: Flow-through of crude 6xHis-tag fused Mu-S5; lane 4-7: eluent from washing $6 \times$ His-tag fused MuS5 with 20, 50, 100 and $300 \mathrm{mM}$ imidazole, respectively. 
(A)

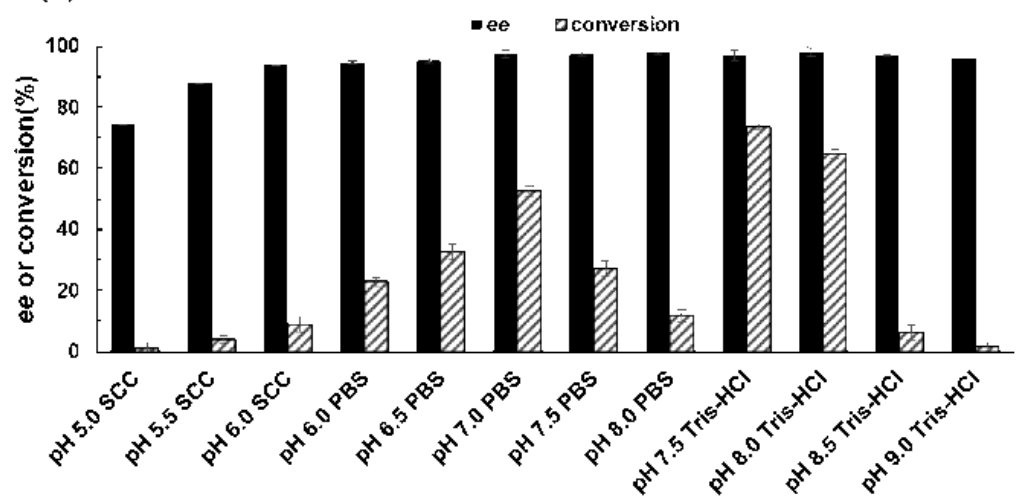

(B)

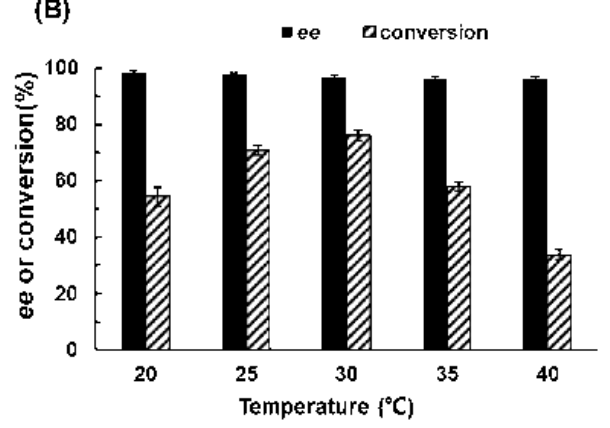

(D)
(C)

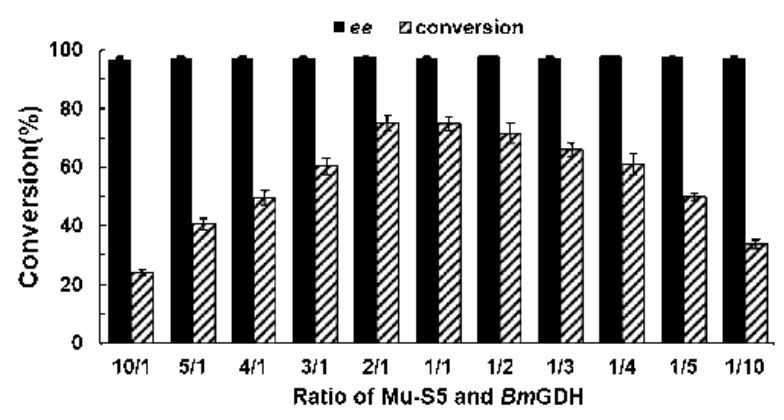

(E)

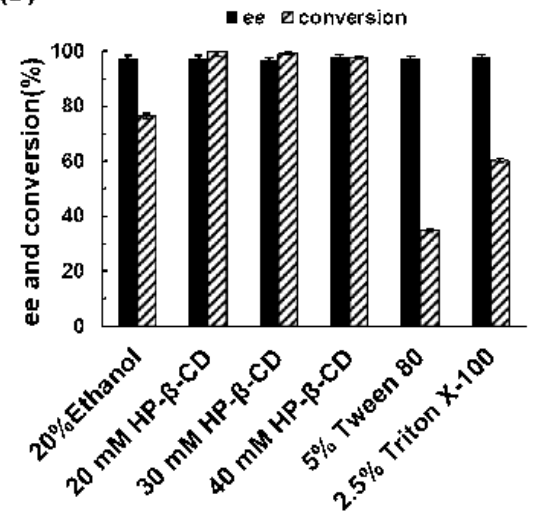

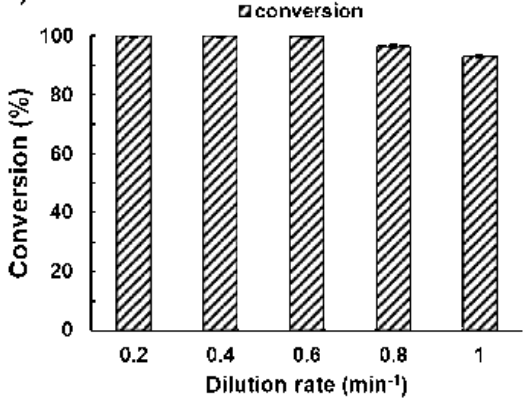

Figure 4

Optimization of reaction catalyzed by immobilized Mu-S5 and BmGDH. (A) $\mathrm{pH}$; (B) temperature; (C) ratio of Mu-S5 and BmGDH; (D) co-solvent; (E) flow rate optimum of (4-chlorophenyl)(pyridine-2-yl)ketone (CPMK) in a 10-mL Ni-functionalized porous ceramic/agarose composite beads (Ni-NTA Cerose) packed bed reactor. 


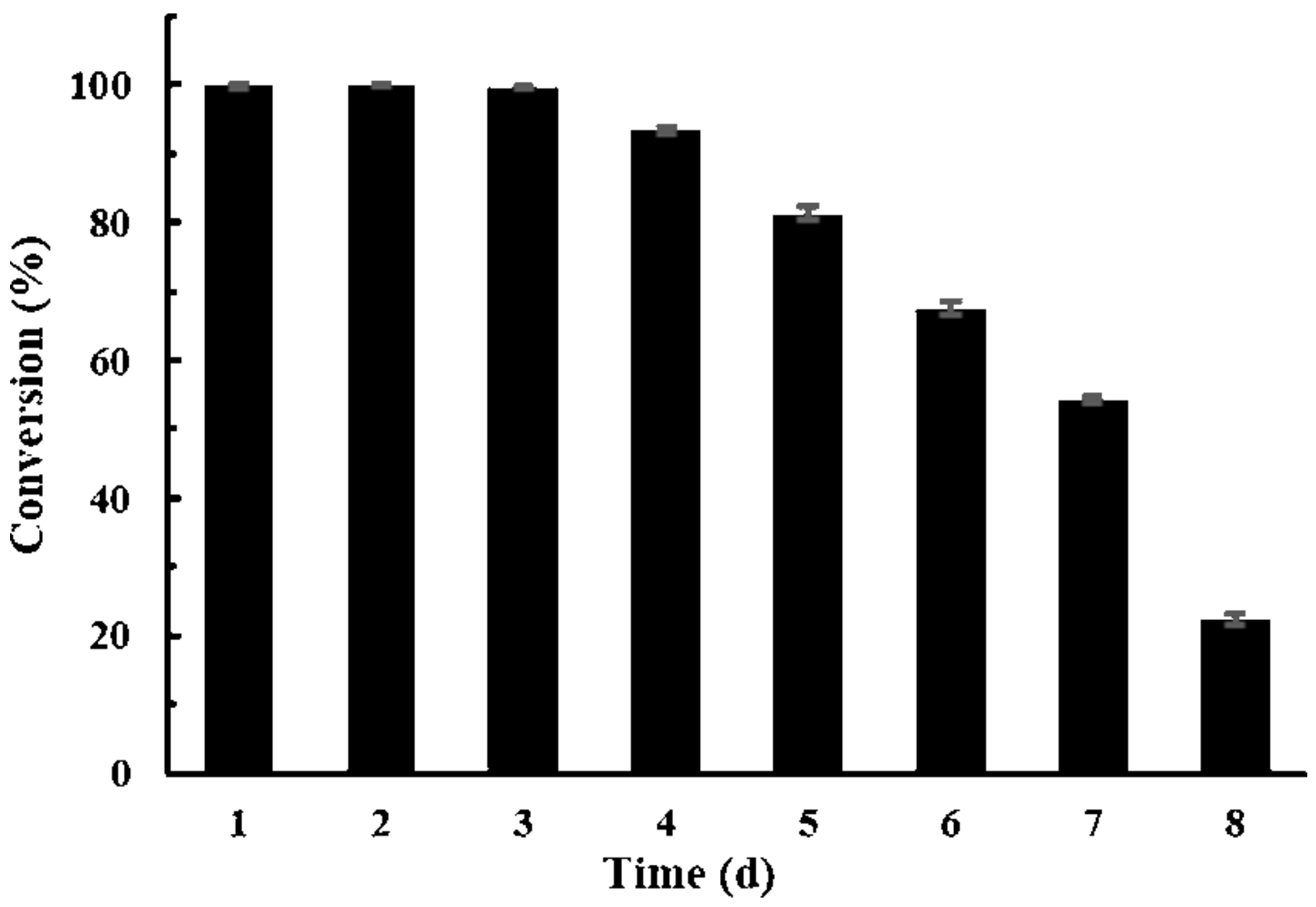

Figure 5

Continuous production of (S)-(4-chlorophenyl)-(pyridin-2-yl) methanol (S-CPMA) in a 10-mL packed bed reactor.

\section{Supplementary Files}

This is a list of supplementary files associated with this preprint. Click to download.

- 2021.2.5supportinginformation.docx 